\title{
Time-shifted Learning
}

\section{Merging Synchronous and Asynchronous Techniques for E-Learning}

\author{
Tom Worthington \\ Research School of Computer Science \\ Australian National University \\ Canberra, Australia \\ tom.worthington@anu.edu.au
}

\author{
$\mathrm{Hao} \mathrm{Wu}$ \\ Research School of Computer Science \\ Australian National University \\ Canberra, Australia \\ wuhao5470@outlook.com
}

\begin{abstract}
E-learning techniques are usually classified into two broad categories: synchronous and asynchronous. The core question of this research is how to combine synchronous and asynchronous techniques in e-learning software, so it can have a stronger connection with constructivist education. The benefits and drawbacks of existing e-learning software is looked at broadly. Three popular elearning packages used at the Australian National University are investigated: Adobe Connect (synchronous), Moodle and edX (asynchronous). The results of a brief survey of edX students is reported. Using the results of this work a team of students at the ANU Research School of Computer Science is now implementing enhanced asynchronous software to be plugged into Moodle and other asynchronous e-learning packages.
\end{abstract}

Index Terms—Asynchronous Learning; Synchronous Learning;

Electronic Learning; Web Conference; Videoconferencing;

Pedagogy

\section{INTRODUCTION}

E-learning involves computers and networks, but also learning activities. The MOOC (Massive Open On-line Course) is popularizing e-learning, with the promise of affordable education for everyone around the world. This term was created in 2008 by Dave Cormier and Bryan Alexander [1]. MOOC development has been rapid; edX having started in May 2012 and after only two years had 2.3 million students [2]. This illustrates e-learning has great potential, but the nature of edX MOOCs and that of the other major providers, are of a far more narrow view of education that envisioned by Cormier and Alexander. This paper explores how to broaden that vision.

While e-learning, particularly MOOCs, appear virtual, they are primarily produced by real universities with campuses and face-to-face education facilities. As an example, the Australian National University (ANU) have an online Learning Management System (LMS) named Wattle, for instructors and students to interact. Such a system can be used for pure elearning, but is more usually used for a hybrid format, blending traditional face-to-face learning and online asynchronous learning. In addition e-learning can use web-conferencing software, such as Adobe Connect for real-time, so called "synchronous" communication [3] [4].

\section{SyNCHRONOUS AND AsYNCHRONOUS TECHNIQUES}

E-learning techniques are usually classified into two broad categories: synchronous and asynchronous. However, the use of these terms by educational theorists exclusively refer to elearning, ignores their role in the traditional face-to-face classroom and assumes they are immutable [5]. This work looks at how synchronous and asynchronous techniques are used, with a view to developing e-learning tools which support both modes seamlessly.

\section{A. Learning Interactions}

Soo and Bonk divided learning activities into four interactions: Learner-Learner, Learner-Instructor, LearnerContent and Learner-Self [6]. Hein pointed out "Learning is intimately associated with our connection with other human beings" [15]. LMS and MOOCs allow for collaboration and communication, but not necessarily in a way which enhances learning. As an example, Vygotsky pointed out that helping students find peers who at a suitable level can significantly improve the quality of collaboration [7].

\section{B. Limitations of Synchronous Software}

Adobe Connect provides synchronous video and voice. A "status" function is provided for students to indicate they need attention, agree, need to "step away" or are having difficulty with the sound. This and other features such as "Question and Answer" allows an on-line simulation of a classroom lecture. Students find this synchronous mode provides good communication with their instructor [3]. However, systems such as Adobe Connect are limited to synchronous communication. After a real time session, students can, at best, use the system to replay a recording, they cannot use the synchronous system for asynchronous communication with fellow students or the instructor.

Cappiccie and Desrosiers designed an experiment which used Adobe Connect to for an online course [3]. Survey results 
showed that students found the video "face to face" contact appealing, however there were technical connectivity problems. Also, the synchronous mode of Adobe Connect requires all the participants to be on-line at same time. This would exclude some students from participating, presumably those students would have a less positive opinion of the software but it is not clear if they were included in Cappiccie and Desrosiers' survey.

Ellingson and Notbohm suggest that due to bandwidth constraints, the webinar class size should limited to 20 distance students [8]. Obviously this would not be sufficient for MOOCs with thousands of students.

\section{Asynchronous Software}

A synchronous system, such as Adobe Connect, is commonly used alongside, or embedded in, an asynchronous LMS, such as Moodle. The interaction between instructors and learners can extend beyond lectures, with the features of the two systems complementing each other. Asynchronous elearning software (such as Moodle) can overcome some of the technical and logistical constraints of synchronous tools, as all students do not need to be on-line at the same time.

Asynchronous communication can overcome the problem of users in different time zones, where it can be difficult to find a time to schedule a lesson for all students. Also students with a first language other than that of instruction can have more time to listen, read (and re-read) material and prepare replies, without the pressure of a real-time forum. Asynchronous mode can also be more easily provided for learner-learner interaction, which not need be confined to on-line. Coughlan reports that groups study "learning hubs" have been held by the MOOC students and these increase the typical completion rate of MOOCs from 5\%-10\% up to 30\%-100\% [11].

\section{BRIEF STUDY OF MOODLE AND OpEN EDX}

Two e-learning tools used at the Australian National University (ANU) were briefly examined for features. The elearning software tools studied were:

- Moodle: A typical LMS which provides primarily asynchronous features, Moodle is provided at the Australian National University (ANU) as part of its Wattle (Web Access to Teaching and Learning Environments) system. An asynchronous package (previously Adobe Connect and later changed to Blackboard Collaborate) is also used as part of what is called ANU's Wattle e-learning system.

- $\quad$ edX: One of the major global MOOC systems, edX was created by MIT and Harvard University [9]. ANU is a member of edX and uses it for free and low cost courses to the public.

\section{A. A Brief Survey of EdX Use at ANU}

Moodle is likely to be reasonably familiar to the reader, but the detail of edX and its "Open edX" software less so. The course "Engaging India” was launched by Dr. Peter Friedlander and Dr. McComas Taylor at ANU, 29 April 2014 as a 10 week edX course. It offers "an overview of contemporary India and explores its role as one of the dominant economic and military powers of Asia” [10]. The course uses collaborative learning, peer grading and instructor based assessment.

With approval of the Engaging India development team at ANU (and ethics clearance) a short survey was designed to investigate the study habits of the students and their opinions of edX. The survey was released to students 1 July 2014 and 66 responses were received over 10 days. From the survey results, 54\% students believe they can have enough communication in edX courses.

TABLE I. DO YOU AGREE STUDENTS HAVE ENOUGH COMMUNICATION WITH EACH OTHER IN EDX?

\begin{tabular}{|l|r|r|}
\hline \multicolumn{1}{|c|}{ Response } & Number & \multicolumn{2}{c|}{ Percent } \\
\hline Strongly Disagree & 3 & $5 \%$ \\
\hline Disagree & 12 & $19 \%$ \\
\hline Not Sure & 14 & $22 \%$ \\
\hline Agree & 28 & $44 \%$ \\
\hline Strongly Agree & 6 & $10 \%$ \\
\hline Total & $\mathbf{6 3}$ & $\mathbf{1 0 0 \%}$ \\
\hline
\end{tabular}

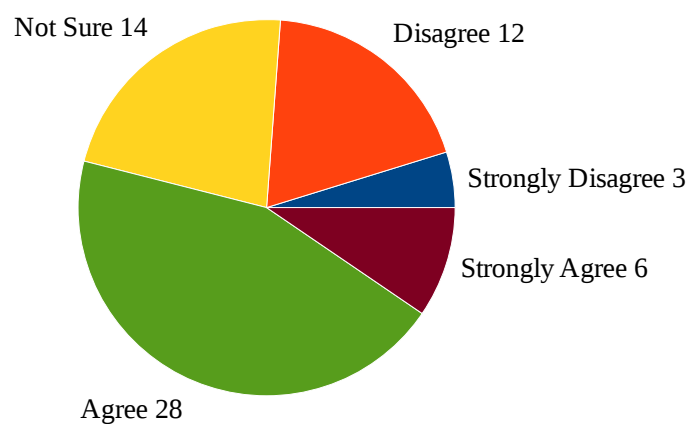

Fig. 1. Do you agree students have enough communication with each other in edX?

The Open edX software has a less mature and extensive suite of functions than current LMS, such as Moodle, due in part to their more recent development and also more specialized requirements for high student volumes with less instructor interaction. However, most students in the survey (72\%) agree edX courses are guiding and mentoring them, not just presenting knowledge.

TABLE II. DO YOU AGREE TEACHERS IN EDX ARE GUIDING AND MENTORING STUDENT'S LEARNING ACTIVITIES, NOT SIMPY GIVING STUDENTS KNOWLEDGE?

\begin{tabular}{|l|r|r|}
\hline \multicolumn{1}{|c|}{ Response } & Number & \multicolumn{2}{c|}{ Percent } \\
\hline Strongly Disagree & 1 & $2 \%$ \\
\hline Disagree & 6 & $10 \%$ \\
\hline Not Sure & 11 & $17 \%$ \\
\hline Agree & 35 & $56 \%$ \\
\hline
\end{tabular}




\begin{tabular}{|l|r|r|}
\hline \multicolumn{1}{|c|}{ Response } & Number & \multicolumn{2}{|c|}{ Percent } \\
\hline Strongly Disagree & 1 & $2 \%$ \\
\hline Strongly Agree & 10 & $16 \%$ \\
\hline Total & 63 & $100 \%$ \\
\hline
\end{tabular}

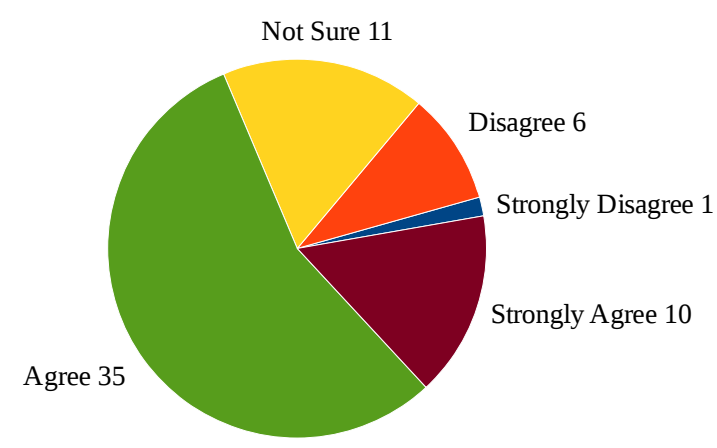

Fig. 2. Do you agree teachers in edX are guiding and mentoring student's learning activities, not simply giving students knowledge?

While students are positive towards edX, there are some drawbacks identified in the literature. The first question is what kind of interaction edX lecture recordings are supplying to participants? EdX provides video recordings, but these do not have all the features of a face-to-face lecture, or a real-time webinar. Learners cannot ask a question or for clarification of a pre-recorded video, only through the discussion boards provided.

\section{CAN E-LEARNing PROVIDE A QuALity EduCATION?}

\section{A. $E d X$}

Instructors can interact with learners via the edX discussion board, or with new video recordings. As an example, the ANU Engaging India edX course provided a weekly video review of student's input. Therefore, it can be said that lecture recordings (instructors to learners), discussion board (both instructors to learners and learners to instructors) and some other communication functions (such as announcements) make up an asynchronous learner-instructor communication system. This communication system and edX's grading system are together provide edX's learner-instructor interaction.

As Huang and Hsiao note, the asynchronous e-learning platforms (such as edX platform) provides for less interaction between learners and instructors and other LMS [12]. However, this may be seen as more a feature of the form of education being provided, rather than due to the tool itself. There are fewer edX tools for student interaction than Moodle or Adobe Connect, but their tools would not scale for large numbers of students expected in a MOOC. Ferenstein states that Coursera, edX and Udacity can have courses of 43,000 students [13].

Reisman has criticized the mass scale education of MOOCs: "It's impossible for a class of tens of thousands (or even of just hundreds) to be well supported by one or even a few instructors.” [14]. This is suggested as one reason for the low completion rate of such courses, with them reliant on learners' self-motivated and self-disciplined learners [14].

Constructivism education theory holds that learning content should have strong connection with the real world [15]. A course using pre-recorded video for large numbers of students, such as those from EdX, can provide content with real world input which is more like a documentary, than a lecture recording. However, the question remains as to if the student can access the video. Liyanagunawardena writes that "many MOOC providers seem to overlook the fact that many people in the developing world still lack broadband access and digital literacies" [16]. In addition, countries such as China, Iran, Pakistan, and Turkmenistan have on occasion blocked the YouTube videos which edX relies on [17].

\section{B. Soft Skills}

A priority for vocationally orientated higher education are so-called "soft skills", such as communication and managing people and it may not seem apparent how these can be gained through a MOOC. Self-reflection has been suggested as a useful for learning soft skills [18]. Soo and Bonk state "One's work may not occur instantly. Some people will deliberately put aside stuff they have written and go back to it some weeks or months later, with a fresh perspective developed in the intervening period." [6].

Synchronous tools, such as Adobe Connect, provides some features for student to reflect, such as the "Note" function. The edX survey indicates that just under half, $48 \%$, or respondents take notes while watching lecture recordings. Asynchronous tools, such as Moodle allows learners link their own blog to Moodle platform. Also the Mahara e-portfolio platform is commonly deployed alongside Moodle for deeper reflection.

\section{Features of the Different Products}

The Open edX and Moodle tools share many features, being primarily asynchronous, whereas Adobe Connect being synchronous has a different feature set. Most course offerings from educational institutions will have an asynchronous base, that is the learner will be assumed to engage with the course in several segments over time. The synchronous tool will therefore normally be embedded in a synchronous LMS.

\section{A Better Webinar ToOl For TEAching}

As has been seen, an synchronous software tool, such as Adobe Connect, can be used with an asynchronous LMS, such as Moodle. However, the level of integration of the tools is limited. As an example, there is limited scope for either instructor, or peer based, assessment within Adobe Connect. To address this, a project "Better Webinar Tool For Teaching” was created in 2015 [19]. The aim is to produce an on-line tool to seamlessly support both asynchronous and asynchronous modes of communication for e-learning, by providing a timeshifting function, similar to that of a Personal Video Recorder. It is also hoped that the same tool can be used for small courses (typically with 25 students) and for MOOCs (with hundreds of thousands of students) by relaxing some of the technical constraints on synchronous software. A team of third and fourth year software engineering students are working on the 
project, with the aim of producing a free open source Moodle plug-in by 2016.

\section{CONCLUSION}

This work looked at some aspects of how e-learning tools are used, and particularly the difference between synchronous and asynchronous techniques. Some results of a brief survey of student experiences in the Australian National University edX course "Engaging India" are presented. A project commenced at ANU to add synchronous functionality to Moodle was introduced.

\section{ACKNOWLEDGMENT}

Thanks to Dr Kim Blackmore, Convener, Digital Learning Project, ANU College of Asia and the Pacific, for access to the ANU edX system and to Professor Tom Gedeon, Head of the ANU Information and Human Centered Computing (iHcc) Research Group for advice on survey procedures.

\section{REFERENCES}

[1] Cormier, D.,"The CCK08 MOOC - Connectivism course, 1/4 way," Dave's Educational Blog. [online], October 2, 2008. Available: http://davecormier.com/edblog/2008/10/02/thecck08-mooc-connectivism-course-14-way/

[2] Rothberg, M. V., “Q \& A with Anant Agarwal,” The Harvard Crimson. Available: http://www. thecrimson. com/article/2014/5/29/Q-and-A-anant-agarwal.

[3] Cappiccie, A.; Desrosiers, P., "Lessons Learned From Using Adobe Connect," Journal of Technology in Human Services, 29 , pp. 296-302, 2011.

[4] Angelopoulos, P.; Paraskevas, M.; Perikos, I.; Zarouchas, T., "A highly motivated blended learning model oriented to computer engineering educators," Computer Science \& Education (ICCSE), 2014 9th International Conference on , vol., no., pp.457,461, 22-24 Aug. 2014 doi: 10.1109/ICCSE.2014.6926503

[5] Worthington, T., "Synchronizing asynchronous learning Combining synchronous and asynchronous techniques," Computer Science \& Education (ICCSE), 2013 8th International Conference on , vol., no., pp.618,621, 26-28 April 2013

doi: 10.1109/ICCSE.2013.6553983

[6] Soo, K. S.; Bonk, C. J., "Interaction: What Does It Mean in Online Distance Education?” Proc. ED-MEDIA/ED-TELECOM 98 World Conference on Educational Multimedia and Hypermedia
\& World Conference on Educational Telecommunications, 1998.

[7] Vygotsky, L. S., "Mind and society: The development of higher mental processes," Cambridge: Harvard University Press, 1978.

[8] Ellingson, D. A.;Notbohm, M., "Synchronous Distance Education:Using Web-Conferencing," American Journal of Business Education, pp. 555-562, September/October, 2012.

[9] Chandler, D. L., "MIT and Harvard launch a 'revolution in education', MIT News, May, 2012. Available: http://newsoffice.mit.edu/2012/edx-launched-0502

[10] ANU., “Engaging India,” edX, 2014. Available: https://www.edx.org/course/anux/anux-anu-india1x-engagingindia-1376\#.U-WpxdKSyQM

[11] Coughlan, S., “Online students can't help being sociable,”. BBC News, April, $2014 . \quad$ Available: http://www.bbc.com/news/business-26925463

[12] Huang, X.; Hsiao, E.L., "Synchronous and Asynchronous Communication in an Online Environment: Faculty Experiences and Perceptions," Quarterly Review of Distance Education 13.1 , pp. 25-30, 2012.

[13] Ferenstein, G., "Study: Massive On-line Courses Enroll An Average Of 43,000 Students, 10\% Completion,” Techcrunch, March, $2014 . \quad$ Available: http://techcrunch.com/2014/03/03/study-massive-onlinecourses-enroll-an-average-of-43000-students-10-completion/

[14] Reisman, S., "The Future of Online Instruction, Part 1," Computer , vol.47, no.4, pp.92,93, Apr. 2014 doi: 10.1109/MC.2014.106

[15] Hein, G. E., “Constructivist Learning Theory," CECA. International Committee of Museum Educators Conference, October, $1991 . \quad$ Available: http://www.exploratorium.edu/ifi/resources/research/constructivi stlearning.html

[16] Liyanagunawardena, T., "MOOC experience: a participant's reflection”. ACM SIGCAS Computers and Society, pp. 44(1): 914, 2014.

[17] Amini, T., "10 Countries That Have Blocked YouTube (And Why),” 2014. Available: http://kotaku.com/10-countries-thathave-blocked-youtube-and-why-1547347768

[18] Smith, G.,; Yates, P., “The benefits of self-reflection,” Training Journal, pp. 49-51, November, 2012. Available: https://www.trainingjournal.com/articles/feature/benefits-selfreflection

[19] Worthington, T., "Better Webinar Tool For Teaching," TechLauncher Project, ANU, 2015. Available: http://cs.anu.edu.au/TechLauncher/project540954.html 